\title{
Erratum to: Expression profiling of familial breast cancers demonstrates higher expression of FGFR2 in BRCA2-associated tumors
}

\author{
Anita L. Bane - Dushanthi Pinnaduwage - Sarah Colby • \\ Michael Reedijk • Sean E. Egan - Shelley B. Bull • \\ Frances P. O'Malley • Irene L. Andrulis
}

Published online: 6 October 2009

(C) Springer Science+Business Media, LLC. 2009

\section{Erratum to: Breast Cancer Res Treat (2009) 117:183-191 DOI 10.1007/s10549-008-0087-1}

Author would like to add the two authors Michael Reedijk and Sean E. Egan to this work and their affiliations are given below.

Author would also like to add the Acknowledgements as given below:

\section{Acknowledgements}

This work was supported by the Canadian Breast Cancer Foundation and the National Cancer Institute under RFA

The online version of the original article can be found under doi:10.1007/s10549-008-0087-1.

A. L. Bane · F. P. O’Malley · I. L. Andrulis

Department of Pathology and Laboratory Medicine, Mount Sinai Hospital, 600 University Ave., Toronto, ON, Canada M5G 1X5

\footnotetext{
A. L. Bane · I. L. Andrulis ( $)$

Fred A. Litwin Centre for Cancer Genetics, \#984 Samuel

Lunenfeld Research Institute, Mount Sinai Hospital, 600

University Ave., Toronto, ON, Canada M5G 1X5

e-mail: andrulis@mshri.on.ca
}

\author{
A. L. Bane - F. P. O’Malley - I. L. Andrulis \\ Department of Pathology and Laboratory Medicine, University \\ of Toronto, Toronto, ON, Canada \\ D. Pinnaduwage $\cdot$ S. Colby $\cdot$ S. B. Bull \\ Prosserman Center for Health Research, Samuel Lunenfeld \\ Research Institute, Mount Sinai Hospital, 600 University Ave., \\ Toronto, ON, Canada M5G 1X5 \\ S. B. Bull \\ Department of Public Health Sciences, University of Toronto, \\ Toronto, ON, Canada
}

\#CA-06-503 as part of the Breast Cancer Family Registry (Breast CFR). The authors thank Dr. Brendan Dickson and Hui Zhang for their technical assistance. We wish to thank the Canadian Cancer Society Research Institute and Terry Fox Foundation for grant support to the Egan lab.

I. L. Andrulis

Department of Molecular and Medical Genetics, University of Toronto, Toronto, ON, Canada

\section{Reedijk}

Department of Surgical Oncology, University Health Network, Toronto, ON, Canada M5G 2M9

M. Reedijk

Department of Surgery, University of Toronto, Toronto, ON, Canada M5G 2M9

\section{Reedijk · S. E. Egan}

Program in Developmental and Stem Cell Biology, Hospital for Sick Children, The Toronto Medical Discovery Tower, 101 College Street, Toronto, ON, Canada M5G 1L7

\section{S. E. Egan}

Department of Molecular Genetics, University of Toronto, Toronto, ON, Canada 